\title{
Trienamine catalyzed asymmetric synthesis and biological investigation of a cytochalasin B-inspired compound collection $\uparrow$
}

14,50

Received 4th November 2015,

Accepted 18th November 2015

DOI: 10.1039/c5ob02272j

www.rsc.org/obc

\author{
Magnus Sellstedt, ${ }^{a}$ Melanie Schwalfenberg, ${ }^{a}$ Slava Ziegler, ${ }^{a}$ Andrey P. Antonchick ${ }^{a}$ \\ and Herbert Waldmann ${ }^{\star a, b}$
}

\begin{abstract}
Due to their enhanced metabolic needs many cancers need a sufficient supply of glucose, and novel inhibitors of glucose import are in high demand. Cytochalasin B (CB) is a potent natural glucose import inhibitor which also impairs the actin cytoskeleton leading to undesired toxicity. With a view to identifying selective glucose import inhibitors we have developed an enantioselective trienamine catalyzed synthesis of a CB-inspired compound collection. Biological analysis revealed that indeed actin impairment can be distinguished from glucose import inhibition and led to the identification of the first selective glucose import inhibitor based on the basic structural architecture of cytochalasin B.
\end{abstract}

\section{Introduction}

Cancer cells adapt to their often hypoxic environment and satisfy their increased need for fast nutrient utilization and metabolic building block generation by shifting their metabolism from oxidative phosphorylation (OXPHOS) to glycolysis even when sufficient oxygen is available. This reprogramming of energy metabolism, termed the Warburg effect, is considered a hallmark of cancer. ${ }^{1}$ To compensate for the lower efficiency of ATP generation in glycolysis as compared to OXPHOS cancer cells upregulate glucose uptake through dysregulated expression of glucose transporters to facilitate import of glucose. In particular, overexpression of glucose transporter GLUT1 has been reported in many types of human cancers. ${ }^{2}$ Small molecule inhibition of glucose uptake via GLUT1 is a promising strategy for the development of novel anti-cancer drug candidates and inhibitors of GLUT1 and related members of the GLUT family are in high demand. ${ }^{3}$ The isoindolinone natural product cytochalasin B (CB; Fig. 1) is a potent GLUT inhibitor ${ }^{4}$ widely used as a biological tool compound. However, CB also inhibits actin

${ }^{a}$ Max-Planck-Institute für Molekulare Physiologie, Otto-Hahn-Strasse 11, 44227 Dortmund, Germany.E-mail: herbert.waldmann@mpi-dortmund.mpg.de

${ }^{b}$ Technische Universität Dortmund, Otto-Hahn-Strasse 6, 44221 Dortmund, Germany $\dagger$ Electronic supplementary information (ESI) available. See DOI: 10.1039/ c5ob02272j

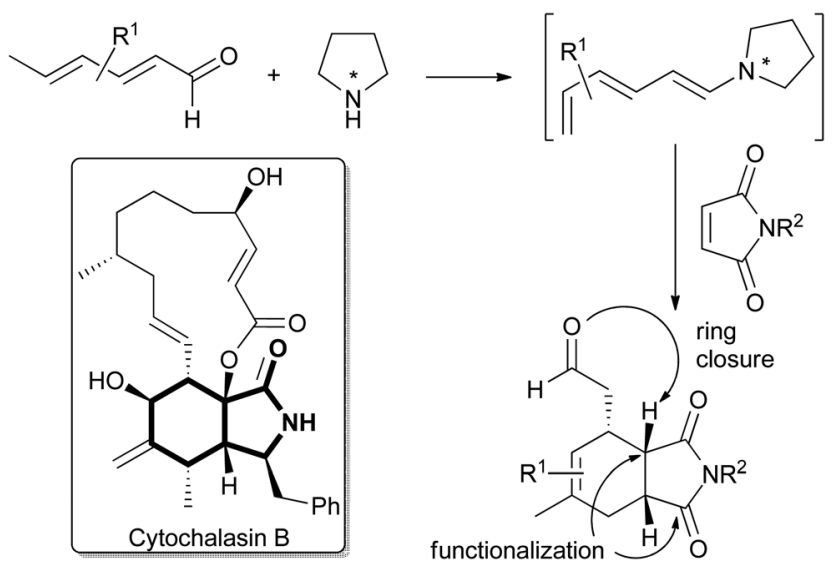

Fig. 1 Structure of cytochalasin B (CB) with the semi-saturated isoindolinone motif highlighted and the outline of the synthesis strategy employing enantioselective trienamine organocatalysis.

polymerization which prevents its use as a drug ${ }^{5}$ and impairs its application as a tool compound in biology. Clearly, the discovery of CB analogs that inhibit GLUT activity but do not impair the actin cytoskeleton would be of major interest. However, to date only sparse data are available that correlate CB activity and structure ${ }^{4}$ and a CB derivative that preferentially inhibits glucose uptake has not been identified. We have now synthesized a CB-inspired compound collection employing enantioselective trienamine catalysis as a key transformation. Biological evaluation of the library revealed the first CBanalogue that inhibits glucose uptake in cancer cells but does not impair actin polymerization.

For the synthesis of cytochalasin B and other cytochalasans an inter- or intramolecular Diels-Alder reaction between a diene- or a triene part and an $\alpha, \beta$-unsaturated amide has been employed as a key step. ${ }^{6}$ Recently, trienamine catalysis has emerged as a powerful method to steer the steric course of asymmetric Diels-Alder reactions, ${ }^{7}$ and we decided to employ this method in the preparation of a cytochalasin inspired compound library. Chen and Jorgensen and co-workers have 
described that linear dienals, which in the presence of prolinederived catalysts form asymmetric trienamines, react with highly activated dienophiles such as cyanoacrylates to form Diels-Alder adducts in high enantiomeric excesses. ${ }^{8}$

However, weaker dienophiles, such as maleimides, did not yield the expected products. Subsequently, maleimides have successfully been reacted with branched $\operatorname{aryl}^{-9}$ and methyl ${ }^{10}$ dienones by using cinchinoa alkaloid derived catalysts. However, the trienamine catalysed reaction between dienals and maleimides which would yield the semi-saturated isoindolinone core of the cytochalasans (Fig. 1) has to the best of our knowledge not yet been reported.

\section{Results and discussion}

We screened various catalysts for the trienamine reaction between dienal $2 \mathbf{2},{ }^{11}$ and maleimide $\mathbf{1 a}$ (Table 1). While we

Table 1 Identification of favorable conditions for the asymmetric trienamine reaction $^{a}$

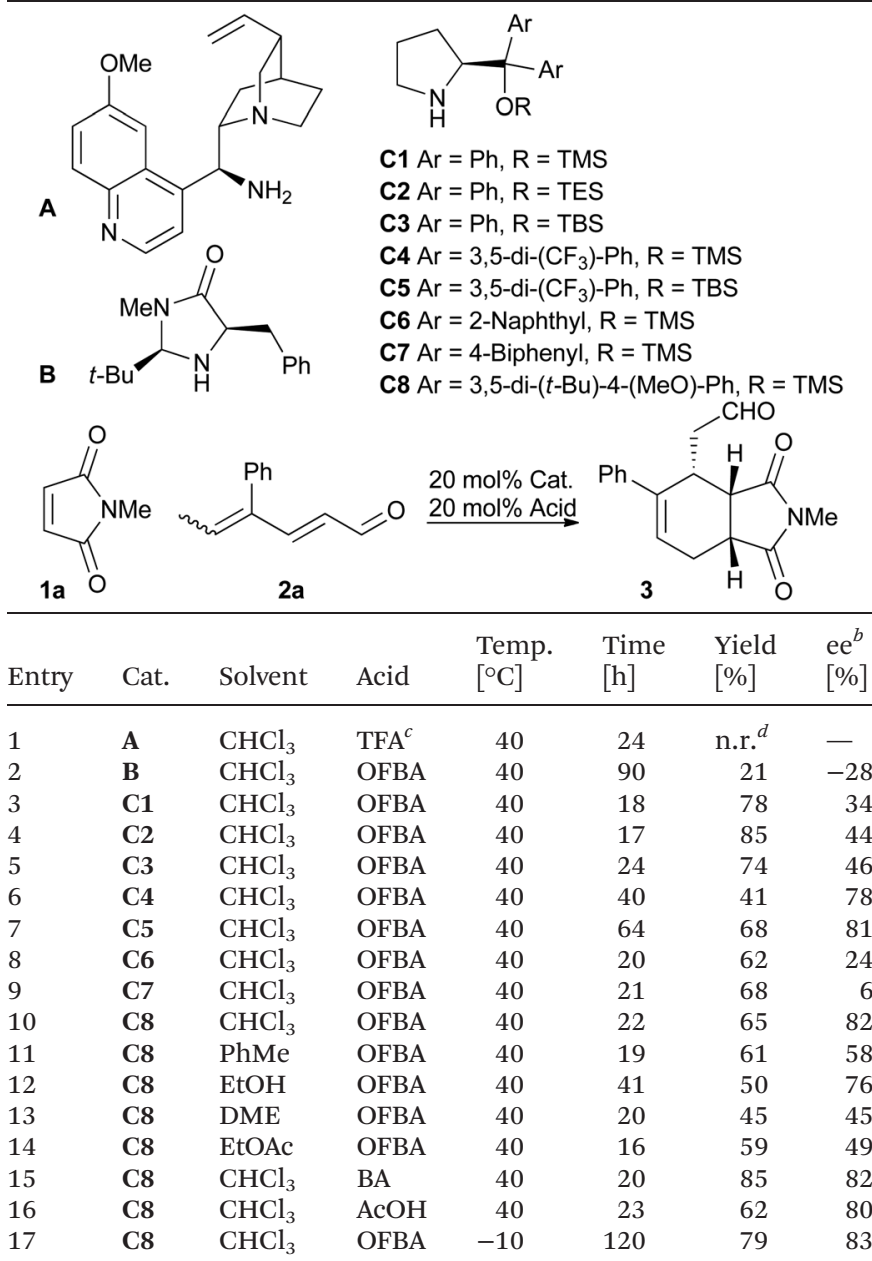

${ }^{a}$ Reaction conditions: 1a $(0.15 \mathrm{mmol})$, 2a (0.165 mmol), catalyst $(0.03 \mathrm{mmol})$, acid $(0.03 \mathrm{mmol})$, solvent $(1.5 \mathrm{~mL}) .{ }^{b}$ The ee was determined by chiral HPLC using a Chiralpak IA column. ${ }^{c} 40 \mathrm{~mol} \%$ acid. ${ }^{d}$ n.r. $=$ no reaction. OFBA $=2$-fluorobenzoic acid, $\mathrm{BA}=$ benzoic acid, $\mathrm{TMS}=$ trimethylsilyl, $\mathrm{TES}=$ triethylsilyl, $\mathrm{TBS}=$ tertbutyldimethylsilyl, TFA = trifluoroacetic acid. were unable to isolate any product using the cinchona-based catalyst A previously used with aryldienones, ${ }^{9}$ the use of the Macmillan catalyst ${ }^{12} \mathbf{B}$ afforded a low yield (21\%) of ent-3 after 90 hours in $28 \%$ ee. Fortunately, the use of diaryl prolinol silyl ethers $\mathbf{C}$ proved more successful. The Jorgensen catalysts ${ }^{13} \mathbf{C} \mathbf{4}$ and $\mathbf{C 5}$ gave much better ee's of $78 \%$ and $81 \%$, respectively. These catalysts, however, significantly decreased the reaction rate compared to the diphenyl analogs $\mathbf{C} \mathbf{1}$ and $\mathbf{C} 3$. The bulky, more electron rich catalyst $\mathbf{C 8}{ }^{14}$ gave the highest ee (82\%) with a reaction rate similar to that of the diphenyl substituted catalysts. The choice of solvent had a substantial impact on the ee, and chloroform was the best among the tested solvents. The acid had only small effects on the ee, but the yield increased by using benzoic acid instead of 2 -fluorobenzoic acid $(85 \%$ and $65 \%$, respectively). Decreasing the temperature to $-10{ }^{\circ} \mathrm{C}$ gave slightly higher ee and also increased the yield. However, as expected, this prolonged the reaction time significantly. The absolute stereochemical outcome of the asymmetric trienamine reaction was confirmed by the preparation of and comparison with a known compound ${ }^{15}$ (see the ESI $\dagger$ ).

To explore the scope of this reaction, various dienals and maleimides were subjected to trienamine catalysis with catalyst C8 (Table 2). The alkyl substituted dienals $2 \mathbf{2 b - \mathbf { d } ^ { 1 1 }}$ were more unstable than the phenyl substituted dienal $2 \mathbf{a}$, and a

Table 2 Scope of the reaction between various maleimides and dienals

\begin{tabular}{|c|c|c|c|c|c|c|c|}
\hline $\begin{array}{l} \\
1 a \\
1 b \\
1 c \\
1 d \\
1 e\end{array}$ & $\begin{array}{l}1^{1}=\mathrm{Me}, \mathrm{F} \\
1^{1}=\mathrm{Bn}, \mathrm{F} \\
1^{1}=\mathrm{Ph}, \mathrm{F} \\
2^{1}=\mathrm{H}, \mathrm{R} \\
1^{1}=\mathrm{Ph}, \mathrm{F}\end{array}$ & $\begin{array}{rl} & 1 \\
= & \mathrm{H} \\
= & \mathrm{H} \\
= & \mathrm{H} \\
\mathrm{H} & \mathrm{H} \\
= & \mathrm{Me}\end{array}$ & $\begin{array}{l}\mathrm{R}^{4} \\
\text { a } \mathrm{R}^{3}=\mathrm{Ph}, \\
\mathrm{b} \mathrm{R}^{3}=\mathrm{H}, \mathrm{F} \\
\mathrm{cR}^{3}=\mathrm{Me}, \\
\mathrm{d} \mathrm{R}^{3}=\mathrm{H}, \mathrm{F}\end{array}$ & $\begin{array}{l}=\mathrm{H}, \mathrm{R}^{5} \\
=\left(\mathrm{CH}_{2}\right. \\
=\mathrm{H}, \mathrm{R}^{5} \\
\mathrm{Me}, \mathrm{R}^{5}\end{array}$ & $\begin{aligned} & =3 \\
= & \mathrm{He} \\
= & \mathrm{H}\end{aligned}$ & $\begin{array}{r}20 \mathrm{~mol} \% \mathrm{C} \\
20 \mathrm{~mol}^{2} \mathrm{PhC} \\
\mathrm{CHCl}_{3}, \mathrm{RT} \text {, th } \\
\mathrm{Ph}_{3} \mathrm{PCHCO} 2 \\
\mathrm{RT}, 24 \mathrm{~h}\end{array}$ & \\
\hline & 4 & & & 5 & & $\begin{array}{ll}6 & \mathrm{R}^{3}=\mathrm{Me}, \mathrm{R} \\
7 & \mathrm{R}^{3,5}=\mathrm{H}, \mathrm{R}\end{array}$ & $\begin{array}{l}1,5=\mathrm{H} \\
=\mathrm{Me}\end{array}$ \\
\hline Entry & Prod. & $\mathrm{R}^{1}, \mathrm{R}^{2}$ & $\begin{array}{l}\text { Time } 1^{\text {st }} \\
\text { step (h) }\end{array}$ & $\begin{array}{l}\text { Yield } \\
(\%)\end{array}$ & $\begin{array}{l}\text { ee } \\
(\%)\end{array}$ & Endo: exo & $E: Z$ \\
\hline 1 & $4 a$ & $\mathrm{H}, \mathrm{H}$ & 22 & 37 & 78 & $18: 1$ & $9: 1$ \\
\hline 2 & $4 b$ & $\mathrm{Bn}, \mathrm{H}$ & 22 & 71 & 72 & $19: 1$ & $19: 1$ \\
\hline 3 & $4 c$ & $\mathrm{Ph}, \mathrm{H}$ & 40 & 75 & 92 & $11: 1$ & $>20: 1$ \\
\hline 4 & $5 a$ & $\mathrm{Me}, \mathrm{H}$ & 24 & 34 & 81 & $9: 1$ & $>20: 1$ \\
\hline 5 & $5 b$ & $\mathrm{Bn}, \mathrm{H}$ & 45 & 25 & 73 & $>20: 1$ & $>20: 1$ \\
\hline 6 & $5 c$ & $\mathrm{Ph}, \mathrm{H}$ & 45 & 46 & 73 & $>20: 1$ & $>20: 1$ \\
\hline 7 & $6 a$ & $\mathrm{Bn}, \mathrm{H}$ & 70 & 58 & 85 & $>20: 1$ & $14: 1$ \\
\hline 8 & $6 b$ & $\mathrm{Ph}, \mathrm{H}$ & 47 & 78 & 85 & $>20: 1$ & $15: 1$ \\
\hline 9 & $7 a$ & $\mathrm{Me}, \mathrm{H}$ & 21 & 71 & 76 & $>20: 1$ & $>20: 1$ \\
\hline 10 & $7 \mathbf{b}$ & $\mathrm{Bn}, \mathrm{H}$ & 21 & 58 & 81 & $>20: 1$ & $>20: 1$ \\
\hline 11 & $7 c$ & $\mathrm{Ph}, \mathrm{H}$ & 21 & 57 & 79 & $>20: 1$ & $>20: 1$ \\
\hline 12 & $7 d$ & $\mathrm{Ph}, \mathrm{Me}$ & 120 & 25 & 82 & $>20: 1$ & $>20: 1$ \\
\hline
\end{tabular}


slightly higher excess (1.5 equiv.) of these dienals was used. The reaction was run at room temperature and the resulting aldehydes were directly treated with a Wittig-reagent to avoid isolation of the somewhat sensitive products. The resulting $\alpha, \beta$-unsaturated esters 4-7 were formed with $72-92 \%$ ee (Table 2).

The reaction tolerated a variety of maleimides and dienals. However, linear dienals such as hexadienal failed to give any notable conversion under these conditions, and when a high concentration of hexadienal was used, the maleimide instead underwent a Diels-Alder reaction with the dienal rather than the trienamine. This is in agreement with the same observation for aryl dienones. ${ }^{9}$ Generally the products were formed in good yields, but compounds 5, which resulted from the least stable dienal, $\mathbf{2 b}$, were obtained in lower yields. Also the 2-methyl substituted maleimide gave a slower reaction and lower yield. The endo-selectivity was good to excellent in all cases.

The prepared $\alpha, \beta$-unsaturated esters are themselves interesting as reactants to construct new, more complex natural
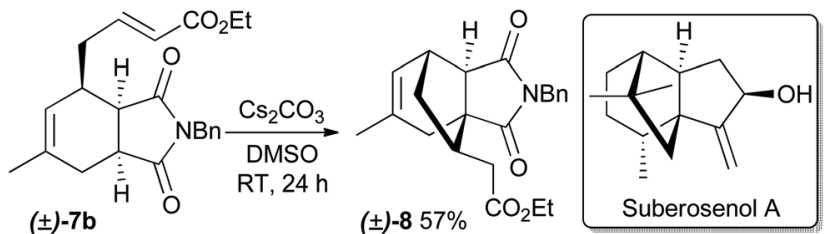

Scheme 1 Intramolecular Michael addition of 7b. product-like heterocycles, as exemplified by the synthesis of compound $\mathbf{8}$ by means of a subsequent highly diastereoselective intramolecular Michael addition (Scheme 1). The configuration of the newly formed stereocenter was determined by NOE measurements. Compound $\mathbf{8}$ has structural similarities to cytotoxic natural products such as quadrone ${ }^{16}$ and suberosenol A. ${ }^{17}$

For the synthesis of a CB-inspired compound collection we envisioned reduction of the intermediate aldehyde formed in the cycloaddition reaction to avoid potential reactivity problems. For establishment of a suitable synthesis sequence initially the cycloadducts were synthesized as racemates in a thermal non-enantioselective Diels-Alder reaction as shown in Scheme 2. To this end, the dienes were equipped either with a methyl ether (9a) or an allyl ether (9b) which would enable subsequent ring closure by means of ring closing metathesis. The obtained imides 10 were then selectively reduced with DIBAL, ${ }^{18}$ activated as sulfones, and then coupled with Grignard-reagents using a zinc-mediated reaction ${ }^{19}$ to produce 11a-g with an additional substituent in the pyrrolidine ring by analogy to the structure of CB. Imides with unprotected $\mathrm{N}-\mathrm{H}$ did not provide the expected products, but the corresponding TBS-protected imides conveniently gave the substituted $\mathrm{N}-\mathrm{H}$ amides 11f-g without a separate deprotection step. Boc-protection of these two amides was necessary for further reactions. To further approximate the CB structure, $\alpha$-hydroxylation of the amide is necessary. For $\alpha$-hydroxylation of related compounds the Davis oxaziridine has previously been employed, ${ }^{20}$ and $\mathbf{1 2 b - c}$ were synthesized using similar conditions. To prepare compounds $\mathbf{1 2 a}$ and $\mathbf{1 2 d}$, however, the reaction with<smiles>C=C(C)C=CCCO</smiles><smiles>[R]C1C(=O)C=CC1=O</smiles>

9a $R^{1}=M e$ $9 b \mathrm{R}^{1}=$ Allyl

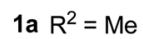

if $R^{2}=P M B$ 1g $R^{2}=T M S E$ $1 \mathrm{~h} \mathrm{R}^{2}=\mathrm{TBS}$

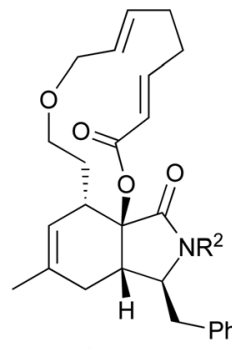

$10 \%$ Grubbs $1^{\text {st }}$ gen. cat. DCM

$35^{\circ} \mathrm{C} \rightarrow \mathrm{RT}, 46 \mathrm{~h}$ for 14a:

14a $R^{2}=H \quad 56 \%$

14b $R^{2}=$ Me $53 \%$

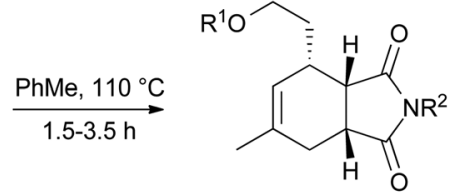

i) $1.2 \mathrm{M}$ DIBAL, $\mathrm{DCM},-78^{\circ} \mathrm{C}, 1 \mathrm{~h}$ ii) $\mathrm{PhSO}_{2} \mathrm{H}$, TMSOTf $0{ }^{\circ} \mathrm{C}, 25 \mathrm{~min}$. iii) $\mathrm{R}^{3} \mathrm{CH}_{2} \mathrm{MgX}, \mathrm{ZnBr}_{2}, \mathrm{THF}$ $0^{\circ} \mathrm{C} \rightarrow \mathrm{RT}$, overnight

10a $R^{1}=M e, R^{2}=M e \quad 85 \%$ 10b $\mathrm{R}^{1}=\mathrm{Me}, \mathrm{R}^{2}=\mathrm{PMB} \quad 84 \%$ 10c $R^{1}=M e, R^{2}=$ TMSE $84 \%$ 10d $R^{1}=\mathrm{Me}, \mathrm{R}^{2}=$ TBS $\quad 77 \%$ 10e $R^{1}=$ Allyl, $R^{2}=$ TBS $86 \%$ 10f $R^{1}=$ Allyl, $R^{2}=\mathrm{Me} \quad 84 \%$

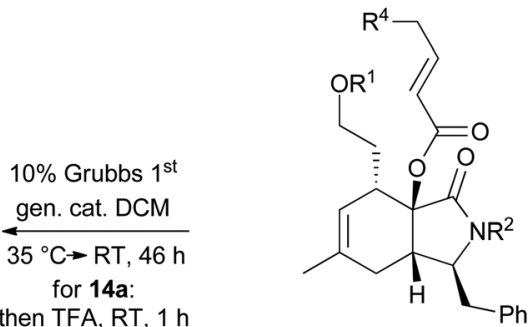

13a $R^{1}=M e, R^{2}=M e, R^{4}=O H \quad 30 \%$ 13b $R^{1}=M e, R^{2}=H, R^{4}=O H \quad 35 \%$ 13c $R^{1}=M e, R^{2}=H, R^{4}=H \quad 52 \%$ 13d $R^{1}=$ Allyl, $R^{2}=$ Boc, $R^{4}=$ Allyl $13 \%$ 13e $R^{1}=$ Allyl, $R^{2}=$ Me, $R^{4}=$ Allyl $14 \%$

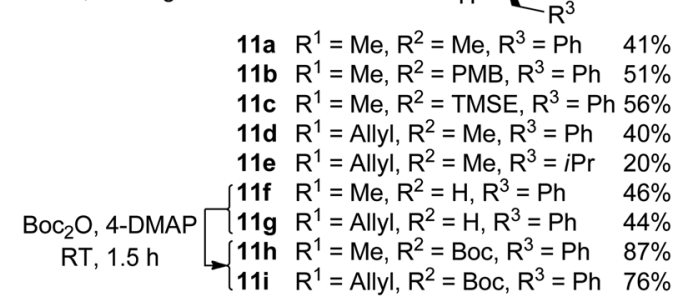

i) $60 \% \mathrm{NaH}, \mathrm{THF}, \mathrm{RT}$<smiles>[R]C/C=C/C(=O)Cl</smiles>

ii) for 13a-b: (+)-CSA $\mathrm{MeOH}, \mathrm{RT}, 1 \mathrm{~h}$

iii) for 13b-c: DCM:TFA 9:1 $\mathrm{RT}, 1 \mathrm{~h}$

11b $R^{1}=M e, R^{2}=P M B, R^{3}=P h \quad 51 \%$

11d $\mathrm{R}^{1}=$ Allyl, $\mathrm{R}^{2}=\mathrm{Me}, \mathrm{R}^{3}=\mathrm{Ph} \quad 40 \%$

11e $R^{1}=$ Allyl, $R^{2}=M e, R^{3}=i \operatorname{Pr} \quad 20 \%$

$11 f R^{1}=M e, R^{2}=H, R^{3}=P h \quad 46 \%$

11i $R^{1}=$ Allyl, $R^{2}=$ Boc, $R^{3}=P h \quad 76 \%$
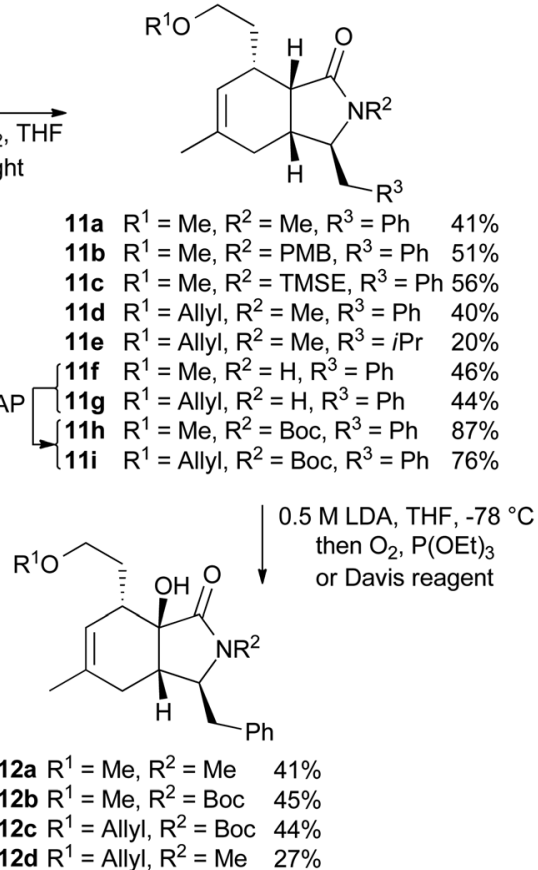

Scheme 2 Synthesis of a CB inspired compound collection. PMB = para-methoxybenzyl, TMSE = 2-trimethylsilylethyl, Boc $=$ tert-butoxycarbonyl. 
dioxygen ${ }^{18}$ was more effective. The tertiary alcohols 12 proved unreactive to coupling with acids using coupling reagents such as carbodiimides, ${ }^{20}$ PyBOP, or HBTU. The alcohols were also unreactive to acid chlorides and 4-DMAP and required deprotonation with sodium hydride to react with acid chlorides. Finally metathesis of 13d-e successfully afforded the macrocyclic compounds $\mathbf{1 4 a - \mathbf { b } ^ { 2 1 }}$ with the same ring-size as CB. Several of the synthesized compounds were also prepared asymmetrically using trienamine catalysis, followed by

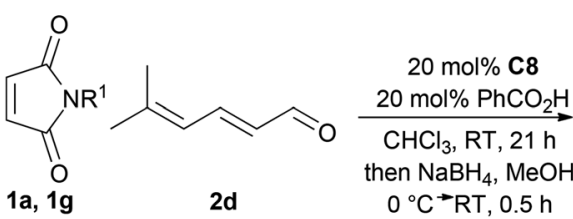

THF, reflux, $25 \mathrm{~h}$
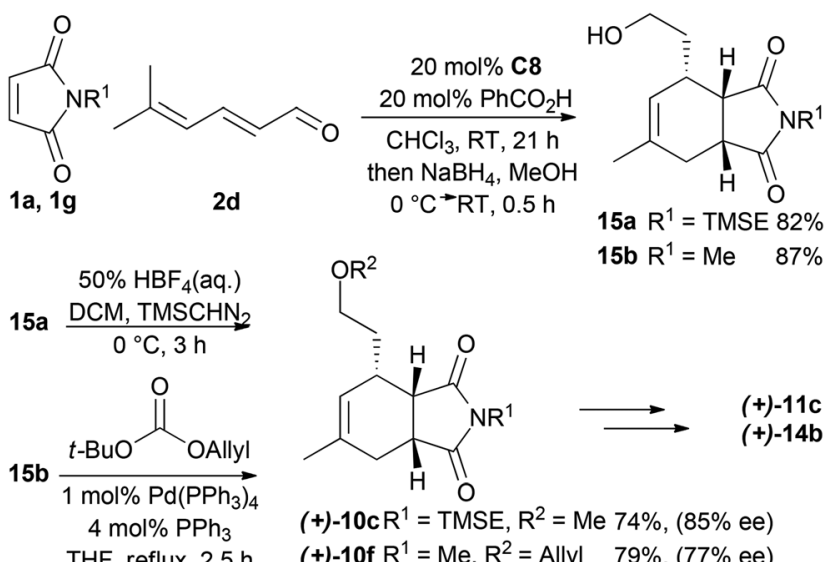

Scheme 3 Asymmetric synthesis of selected compounds.

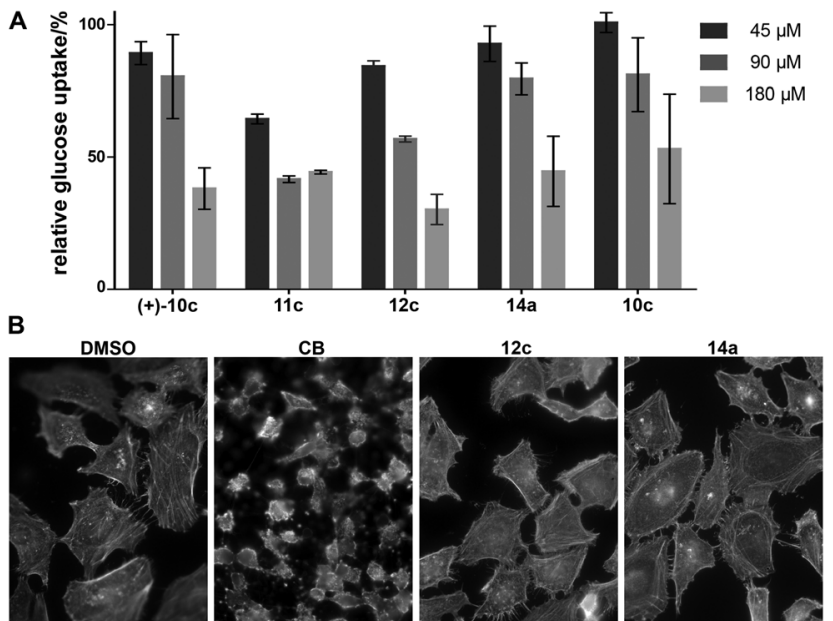

Fig. 2 Influence of selected compounds on glucose uptake and the actin cytoskeleton. (A) Glucose uptake was determined in HCT116 cells upon treatment with 2-deoxy-D-glucose (2DG) and with the compounds or DMSO as a control for 30 min followed by detection of 2DG uptake by means of an enzyme coupled reaction using glucose-6-phospate dehydrogenase, $\mathrm{NADP}^{+}$and diaphorase to reduce weakly fluorescent resazurin to highly fluorescent resorufin. Data are shown as mean values $(n=3) \pm$ s.d. and were normalized to DMSO. (B) The influence of 12c and $14 \mathrm{a}$ on the actin cytoskeleton was investigated in HeLa cells. Cells were treated with the compound or DMSO and CB as a control for $1 \mathrm{~h}$ prior to fixation and staining of actin using phalloidin labelled with TRITC. Nuclei were stained with DAPI. reduction with sodium borohydride, and then either methylation with TMS-diazomethane, or allylation with tert-butyl-allyl carbonate $^{22}$ (Scheme 3).

The compounds 4-8 and 10-15 were then investigated for inhibition of glucose import in the human colon cancer cell line HCT116 using a 2-deoxyglucose-based assay. ${ }^{23}$ Compounds which showed significant inhibition at the initially employed concentration of $180 \mu \mathrm{M}$ were also analysed at $90 \mu \mathrm{M}$ and $45 \mu \mathrm{M}$. The results revealed that compounds which embody the partially saturated isoindolinone core of $\mathrm{CB}$ but lack the medium-sized lactone ring can inhibit glucose import as was in particular observed for 11c and 12c (Fig. 2A). The absolute configuration of these cycloadducts is only of minor importance. These compounds carry only a substituent in the cyclohexane ring and a benzyl group in the pyrrolidine. Analogous bicyclic compounds with an additional substituent $\alpha$ to the carbonyl group (13) were not active. Notably, compound 14a which contains the macrocyclic ring was active in the glucose import assay. Bicyclic compound 12c and tricyclic CB analog 14a were finally investigated for possible influence on the actin cytoskeleton (Fig. 2B). Very gratifyingly, at $180 \mu \mathrm{M}$ concentration both compounds did not impair the actin cytoskeleton in cells.

\section{Conclusions}

Our results demonstrate that it is indeed possible to differentiate the glucose import inhibiting activity of cytochalasin B from its influence on actin polymerization. Structurally significantly simplified $\mathrm{CB}$ analogs 12c and 14a are the first compounds that on the one hand resemble the characteristic structural architecture of the natural product at the scaffold level, yet are glucose import inhibitors only. Clearly, these compounds do not reach the potency of the natural product itself, and our data in accord with previous findings ${ }^{4,5}$ indicate that structural fine-tuning of the macrocycle and the partially saturated isoindolinone scaffold is necessary for full activity. However, they also suggest that by means of appropriate structure-activity correlation it may be possible to develop potent glucose import inhibitors based on the structure of cytochalasin B which are devoid of undesired impact on the actin cytoskeleton.

\section{Experimental}

Detailed experimental procedures and analytical data are described in the ESI. $\dagger$

\section{Acknowledgements}

We gratefully acknowledge the European Research Council under the European Union's Seventh Framework Program (FP7/2007-2013) (grant no. 268309) (H. Waldmann) and the 
Swedish Research Council (grant no. 350-2012-6611) (M. Sellstedt) for financial support.

\section{Notes and references}

1 (a) D. Hanahan and R. A. Weinberg, Cell, 2011, 144, 646674; (b) G. Kroemer and J. Pouyssegur, Cancer Cell, 2008, 13, 472-482; (c) M. G. Vander Heiden, L. C. Cantley and C. B. Thompson, Science, 2009, 324, 1029-1033.

2 (a) R. A. Cairns, I. S. Harris and T. W. Mak, Nat. Rev. Cancer, 2011, 11, 85-95; (b) N. El Mjiyad, A. CaroMaldonado, S. Ramirez-Peinado and C. Munoz-Pinedo, Oncogene, 2011, 30, 253-264.

3 (a) J. B. Park, J. Nat. Prod., 2001, 64, 381-384; (b) Y. Patel and A. Harmon, FASEB J., 2004, 18, A897-A897; (c) X. Cao, L. Fang, S. Gibbs, Y. Huang, Z. Dai, P. Wen, X. Zheng, W. Sadee and D. Sun, Cancer Chemother. Pharmacol., 2007, 59, 495-505; (d) T. E. Wood, S. Dalili, C. D. Simpson, R. Hurren, X. Mao, F. S. Saiz, M. Gronda, Y. Eberhard, M. D. Minden, P. J. Bilan, A. Klip, R. A. Batey and A. D. Schimmer, Mol. Cancer Ther., 2008, 7, 3546-3555; (e) M. Shanmugam, S. K. McBrayer, J. Qian, K. Raikoff, M. J. Avram, S. Singhal, V. Gandhi, P. T. Schumacker, N. L. Krett and S. T. Rosen, J. Biol. Chem., 2009, 284, 26816-26830; $(f)$ D. A. Chan, P. D. Sutphin, P. Nguyen, S. Turcotte, E. W. Lai, A. Banh, G. E. Reynolds, J.-T. Chi, J. Wu, D. E. Solow-Cordero, M. Bonnet, J. U. Flanagan, D. M. Bouley, E. E. Graves, W. A. Denny, M. P. Hay and A. J. Giaccia, Sci. Transl. Med., 2011, 3; $(g)$ I. García-Álvarez, L. Garrido and A. Fernández-Mayoralas, ChemMedChem, 2007, 2, 496-504; (h) O. A. Ulanovskaya, J. Cui, S. J. Kron and S. A. Kozmin, Chem. Biol., 2011, 18, 222-230; (i) D. Wang, P.-C. Chu, C.-N. Yang, R. Yan, Y.-C. Chuang, S. K. Kulp and C.-S. Chen, J. Med. Chem., 2012, 55, 38273836; (j) Y. Liu, Y. Cao, W. Zhang, S. Bergmeier, Y. Qian, H. Akbar, R. Colvin, J. Ding, L. Tong, S. Wu, J. Hines and X. Chen, Mol. Cancer Ther., 2012, 11, 1672-1682; (k) C. Granchi and F. Minutolo, ChemMedChem, 2012, 7, 1318-1350; (l) I. Heisler, T. Müller, S. Golz, J. Telser, H. Rehwinkel, H. Siebeneicher, B. Buchmann, L. Zorn, K. Eis and M. Koppitz, Patent, WO2013182612, 2013.

4 (a) A. L. Rampal, H. B. Pinkofsky and C. Y. Jung, Biochem., 1980, 19, 679-683; (b) J. F. Griffin, A. L. Rampal and C. Y. Jung, Proc. Natl. Acad. Sci. U. S. A., 1982, 79, 37593763.

5 (a) T. Hirose, Y. Izawa, K. Koyama, S. Natori, K. Iida, I. Yahara, S. Shimaoka and K. Maruyama, Chem. Pharm.
Bull., 1990, 38, 971-974; (b) I. Yahara, F. Harada, S. Sekita, K. Yoshihira and S. Natori, J. Cell Biol., 1982, 92, 69-78.

6 (a) K. Scherlach, D. Boettger, N. Remme and C. Hertweck, Nat. Prod. Rep., 2010, 27, 869-886; (b) G. Stork, Y. Nakahara, Y. Nakahara and W. J. Greenlee, J. Am. Chem. Soc., 1978, 100, 7775-7777; (c) A. Craven, D. J. Tapolczay, E. J. Thomas and J. W. F. Whitehead, J. Chem. Soc., Chem. Commun., 1985, 145-147.

7 (a) H. Jiang, L. Albrecht and K. A. Jorgensen, Chem. Sci., 2013, 4, 2287-2300; (b) J.-L. Li, T.-Y. Liu and Y.-C. Chen, Acc. Chem. Res., 2012, 45, 1491-1500.

8 Z.-J. Jia, H. Jiang, J.-L. Li, B. Gschwend, Q.-Z. Li, X. Yin, J. Grouleff, Y.-C. Chen and K. A. Jorgensen, J. Am. Chem. Soc., 2011, 133, 5053-5061.

9 X.-F. Xiong, Q. Zhou, J. Gu, L. Dong, T.-Y. Liu and Y.-C. Chen, Angew. Chem., Int. Ed., 2012, 51, 44014404.

10 P.-Q. Chen, Y.-C. Xiao, C.-Z. Yue and Y.-C. Chen, Org. Chem. Front., 2014, 1, 490-493.

11 Z.-J. Jia, Q. Zhou, Q.-Q. Zhou, P.-Q. Chen and Y.-C. Chen, Angew. Chem., Int. Ed., 2011, 50, 8638-8641.

12 A. B. Northrup and D. W. C. MacMillan, J. Am. Chem. Soc., 2002, 124, 2458-2460.

13 J. Franzen, M. Marigo, D. Fielenbach, T. C. Wabnitz, A. Kjaersgaard and K. A. Jorgensen, J. Am. Chem. Soc., 2005, 127, 18296-18304.

14 Y.-k. Liu, C. Ma, K. Jiang, T.-Y. Liu and Y.-C. Chen, Org. Lett., 2009, 11, 2848-2851.

15 CCDC 864374, available from http://www.ccdc.cym.uk/ data_request/cif.

16 R. L. Ranieri and G. J. Calton, Tetrahedron Lett., 1978, 499502.

17 J. H. Sheu, K. C. Hung, G. H. Wang and C. Y. Duh, J. Nat. Prod., 2000, 63, 1603-1607.

18 M. Y. Kim, J. E. Starrett and S. M. Weinreb, J. Org. Chem., 1981, 46, 5383-5389.

19 Y. Arai, M. Matsui, A. Fujii, T. Kontani, T. Ohno, T. Koizumi and M. Shiro, J. Chem. Soc., Perkin Trans. 1, 1994, 25-39.

20 A. M. Haidle and A. G. Myers, Proc. Natl. Acad. Sci. U. S. A., 2004, 101, 12048-12053.

21 The $E$ : $Z$-selectivity in the macrocyclizations were about $1.5-2: 1$. The $Z$-isomers obtained were not fully analytically pure, but appeared to be significantly less active than their $E$-counterparts as glucose uptake inhibitors.

22 J. M. Kraus, H. C. Gits and R. B. Silverman, Tetrahedron Lett., 2012, 53, 1319-1322.

23 N. Yamamoto, M. Ueda, T. Sato, K. Kawasaki, K. Sawada, K. Kawabata and H. Ashida, Curr. Protoc. Pharmacol., 2011, 55, 12.14.51-12.14.22. 